\title{
Activated Notch1 interacts with p53 to inhibit its phosphorylation and transactivation
}

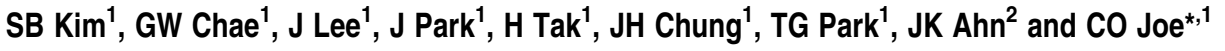

We propose a biochemical mechanism for the negative role of Notch signaling on p53 transactivation function. Expression of the intracellular domain of human Notch1 (Notch1-IC) inhibits the expression of p53-responsive genes p21, mdm2, and bax in HCT116 $p 53^{-1-}$ cells. Furthermore, Notch1-IC expression inhibits the phosphorylation of ectopically expressed p53 in HCT116 $p 53^{-I-}$ cells as well as the phosphorylation of endogenous $\mathrm{p} 53$ in UV-treated HCT116 $p 53^{+I+}$ cells. Transcriptional downregulation of p53-responsive genes by Notch1-IC was confirmed both by chromatin immunoprecipitation assay and Northern blot analysis. We found the intracellular interaction between Notch1-IC and p53 in HCT116 $p 53^{+I+}$ cells and suggest that activated Notch1 interaction with p53 is an important cellular event for the inhibition of p53-dependent transactivation. The $\mathrm{N}$-terminal fragment of Notch1-IC, which can interacts with p53, inhibits p53 phosphorylation and represses p53 transactivation. In addition, Notch signaling downregulated p53-dependent apoptosis induced by UV irradiation.

Cell Death and Differentiation (2007) 14, 982-991. doi:10.1038/sj.cdd.4402083; published online 22 December 2006

The Notch gene family, first identified in Drosophila melanogaster, has been identified and characterized in a variety of animal models. ${ }^{1}$ Notch proteins are large but highly conserved transmembrane receptor proteins that mediate cellular signals involved in cell fate decisions. ${ }^{2}$ In vertebrates, Notch proteins comprise a family of four transmembrane receptors (Notch1-4) that are highly related to each other and to homologues in Drosophila and Caenorhabditis elegans. The extracellular domain of each Notch receptor includes EGF-like repeats followed by the Cys-rich Notch/Lin12 domain, whereas the intracellular domain contains a RAM domain, six ankyrin repeats, a transactivation domain, and a PEST sequence. Thus far, six mammalian Notch ligands have been identified including Delta-like homologues DLL1, DLL2, DLL3, and DLL4 and Serrate-like homologues JAG1 and JAG2. ${ }^{2}$

Notch signaling is initiated by interaction between the receptor and its ligand. Ligand binding leads to proteolytic cleavage near the transmembrane region of Notch intracellular domain, resulting in release of the intracellular domain (Notch-IC). Notch-IC enters the nucleus and binds to a CSL transcription factor. CBF1 (also known as RBP-Jk), the mammalian homologue of $D$. melanogaster Suppressor of Hairless, is an important CSL transcription factor in mammalian cells. After association with CBF1, Notch-IC stimulates the expression of target genes through recruitment of transcriptional coactivators such as histone acetyl transferases. ${ }^{3}$ Among the best-characterized downstream targets of Notch signaling in mammals are HES gene family members, which are known to inhibit the expression of genes involved in neuronal differentiation. ${ }^{4}$ Activated Notch1 also induces p21 expression either by CBF1-dependent or CBF1independent transcriptional regulation in primary mouse keratinocytes. ${ }^{5}$ Increased expression of the cell cycle regulator p21 causes cell cycle arrest and helps to trigger terminal differentiation. Thus, Notch signaling can either activate or inhibit a variety of cellular processes including cell cycling, differentiation, proliferation, and death. These Notchinfluenced processes are all important in the context of the roles of Notch signaling in tumorigenesis.

The oncogenic role of Notch was first illustrated in T-cell acute lymphoblast leukemia. ${ }^{6}$ Whether Notch signaling plays a critical role in neoplastic transformation is unknown, but there is evidence to suggest oncogenic properties of Notch signaling. Overexpression of activated human Notch family members was observed in translocation-associated T-cell acute lymphoblast leukemia. ${ }^{7,8}$ Activated Notch1 can induce neoplastic transformation in mouse mammary and salivary glands and in rat kidney cells in vitro. ${ }^{9,10}$ Notch signaling was reported to be required for neoplastic transformation in Ras-transformed human breast cancer cells. ${ }^{11}$ Increased expression of activated Notch proteins and enhanced Notch signaling were shown in human colon adenocarcinoma. ${ }^{12}$ The establishment of an immortalized hematopoietic cell line by constitutive Notch1 signaling strongly illustrates the oncogenic properties of Notch. However, controversial roles for the involvement of Notch signaling in tumorigenesis have been presented. Studies have shown that Notch signaling is not exclusively oncogenic but can also be tumor-suppressive. For example, Notch1-deficient mice develop basal-cellcarcinoma-like tumors and are highly susceptible to

\footnotetext{
${ }^{1}$ Department of Biological Sciences, Korea Advanced Institute of Science and Technology, Daejeon, South Korea and ${ }^{2}$ Department of Microbiology, Chungnam National University, Daejeon, South Korea

${ }^{*}$ Corresponding author: CO Joe, Department of Biological Sciences, Korea Advanced Institute of Science and Technology, Daejeon 305-701, South Korea.

Tel. + 8242869 2627; Fax: + 8242869 2610; E-mail: cojoe@ kaist.ac.kr

Keywords: p53; Notch; apoptosis; phosphorylation; tumor suppressor

Abbreviations: ChIP, chromatin immunoprecipitation; EMSA, electrophoretic mobility shift assay; PARP, poly(ADP-ribose) polymerase; GST, glutathione $S$-transferase

Received 17.5.06; revised 11.10.06; accepted 02.11.06; Edited by B Osborne; published online 22.12.06
} 
chemical-induced carcinogenesis, suggesting a tumor suppressor function for Notch. ${ }^{13}$ In addition, activated Notch1 inhibits the growth of mouse prostate cancer cells and functions as a tumor suppressor. ${ }^{14}$

p53 is a transcription factor and a tumor suppressor protein that controls cell proliferation and counteracts the effects of oncogene activation. ${ }^{15}$ Activation of wild-type p53 in response to DNA damage results in either growth arrest or apoptosis by inducing the expression of downstream target genes including p21, which encodes an inhibitor of cyclin-dependent kinase to block cell cycle progression ${ }^{16}$ and proapoptotic gene such as bax. ${ }^{17}$ In this study, we propose a mechanism by which Notch signaling represses the p53-dependent transactivation based on the observations that activated Notch1 interacts with p53, inhibits p53 phosphorylation, and interferes with sequencespecific p53 DNA binding resulting in the inhibition of p53dependent transactivation and subsequent inactivation of p53-dependent apoptotic pathway in human cancer cells.

\section{Results}

Activated Notch1 Represses p53 Transactivation. To determine whether Notch signaling is capable of counteracting the tumor-suppressive properties of $p 53$, we evaluated the effects of transiently expressed intracellular domain of human Notch1 (Notch1-IC) on p53 transactivation. HCT116 p53 ${ }^{-1-}$ cells were cotransfected with p53 expression vector, varying amounts of plasmid encoding Notch1-IC, and luciferase reporter plasmid containing one of the promoters of $p 21, m d m 2$, and bax. Subsequent luciferase assay revealed a dose-dependent inhibition of p53 transactivation by transient expression of Notch1-IC (Figure 1a). Notch1-IC expression also reduced endogenous expression of p53 target genes such as p21, mdm2, and PUMA in HCT116 $p 53^{-/-}$cells, suggesting the downregulation of p53 transactivation by Notch signaling (Figure 1b). The transcriptional downregulation of p53-responsive p21 gene was confirmed by Northern blot analysis. The transcription of $p 21$ gene in UV-treated HCT116 $p 53^{+/+}$cells was evidently reduced by Notch1-IC expression (Figure 1c). The negative role of Notch signaling on the regulation of tumor-suppressive p53 transcriptional activity does not seem to be restricted to HCT116 human colon cancer cells, as Notch1-IC expression also inhibited p53 transactivation in COS monkey kidney cancer cells and HeLa human cervical cancer cells (Figure 1d).

Notch1-IC Inhibits p53 phosphorylation and p53 DNA binding. We examined the effects of Notch signaling on p53 phosphorylation and DNA binding. The phosphorylation of p53 was analyzed using phospho-specific antibodies against p53 phosphorylated at specific Ser residues. Expression of Notch1-IC in HCT116 $p 53^{-1-}$ cells inhibited the phosphorylation of ectopically expressed p53 at Ser 6, 9, 15,37 , and 46 in the $\mathrm{N}$-terminal region of p53 (Figure 2A). Notch1-IC expression also inhibited the phosphorylation of endogenous p53 induced by DNA damage in HCT116 $p 53^{+1+}$ cells irradiated with $30 \mathrm{~J} / \mathrm{m}^{2}$ UV $(254 \mathrm{~nm})$. The phosphorylation of $\mathrm{p} 53$ at Ser residues was analyzed immediately or $8 \mathrm{~h}$ after UV irradiation. Cellular levels of endogenous p53 increased after UV irradiation, and became phosphorylated at Ser 15 and 37 in response to UV DNA damage. However, the phosphorylation of endogenous p53 was decreased by Notch1-IC expression in UV-treated HCT116 $p 53^{+/+}$cells (Figure 2B). We sought to confirm the inhibition of $p 53$ phosphorylation by Notch signaling in Notch1 knockdown cells transfected with siRNA. The silencing of Notch1 was evident in UV-treated HCT116 $p 53^{+1+}$ cells after transfection with siRNA, specific for human Notch1. The phosphorylation of p53 at Ser 15 and 37 was restored by Notch1 siRNA transfection, but transfection of control siRNA did not affect p53 phosphorylation (Figure 2C). To determine whether the activated Notch1 interferes with the ability of $\mathrm{p} 53$ to bind its recognition sites on DNA, p53 binding to the double-stranded oligonucleotide probes containing the recognition site either in GADD45 or p21 promoter was analyzed by electrophoretic mobility shift assay (EMSA). The ability of p53 to bind both recognition sites was markedly affected by Notch1-IC expression in HCT116 $p 53^{-1-}$ cells (Figure 2D). To test whether Notch signaling interferes with the binding of p53 to cellular promoter regions of p53 downstream target genes in cells, chromatin immunoprecipitation (ChIP) analysis was performed. Notch1-IC expression impaired the binding of p53 to the promoters of p21 and PUMA in cotransfected cells (Figure 2E).

Notch1-IC Interacts with p53. Coimmunoprecipitation experiments were performed to examine whether activated Notch1 physically interacts with p53. Notch1 was present in both HCT116 $p 53^{+/+}$and HCT116 $p 53^{-1-}$ cells, whereas p53 was detected only in HCT116 p53 ${ }^{+/+}$cells (Figure 3A, a, left). The interaction between endogenous Notch1 and p53 was detected by coimmunoprecipitation. Notch1 was coimmunoprecipitated with p53 from HCT116 $\mathrm{p5}^{+/+}$cells (Figure 3A, a). Likewise, endogenous p53 protein from HCT116 $p 53^{+l+}$ cells was also coimmunoprecipitated with endogenous Notch1 protein (Figure 3A, b). Intermolecular association between FLAG-tagged Notch1-IC deletion derivatives and glutathione $S$-transferase (GST) -fused p53 was also examined. Results from the GST pull-down assay suggest that the N-terminal region of FLAG-tagged Notch1IC binds effectively with GST-fused p53 in cotransfected HCT116 $\mathrm{p53}^{-1-}$ cells (Figure 3B). Examination of intermolecular association between FLAG-tagged p53 deletion derivatives and GST-fused Notch1-IC in cotransfected HCT116 $p 53^{-1-}$ cells showed that the $\mathrm{N}$-terminal region of p53 protein is important for the interaction between Notch1IC and p53 (Figure $3 \mathrm{C}$ ). Collectively, these data suggest that the $\mathrm{N}$-terminal region of Notch1-IC interacts with the $\mathrm{N}$-terminal region of $\mathrm{p} 53$.

The N-terminal fragment of Notch1-IC represses p53 transactivation. In an attempt to understand the relationship between Notch1-IC interaction with p53 and the repression of p53 transactivation, the effects of the $\mathrm{N}$-terminal and C-terminal fragment of Notch1-IC on the repression of p53 transactivation were studied. Our data demonstrate that the ability of Notch1-IC to interact with p53 

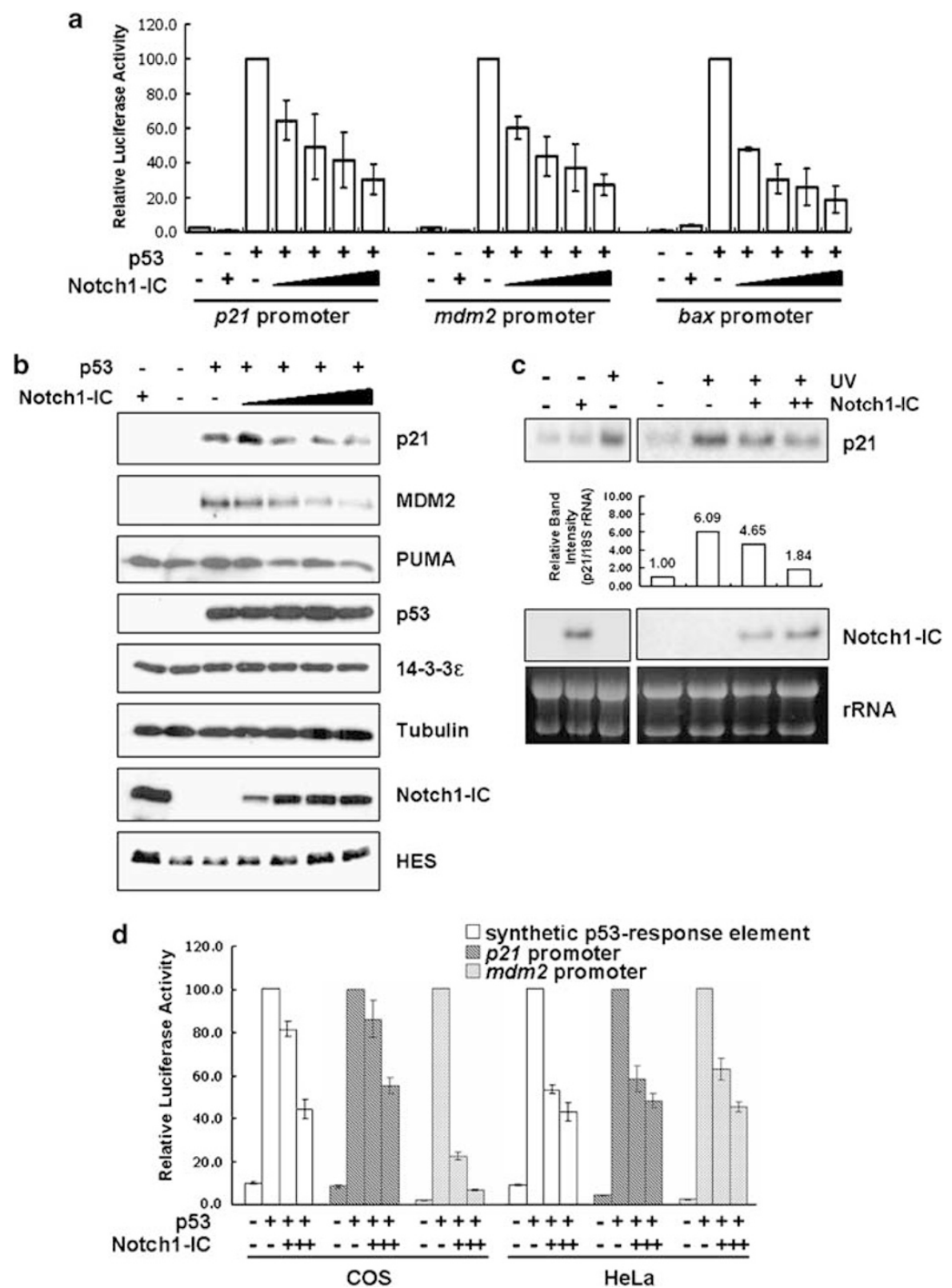

Figure 1 Notch signaling represses p53 transactivation. (a) Effects of transiently expressed Notch1-IC on p53 transactivation. HCT116 p53-l- cells $\left(2 \times 10^{5}\right)$ were cotransfected with p53 expression vector (100 ng) and luciferase reporter (100 ng each) containing one of the promoters of p21, mdm2, and bax together with increasing amounts $(100,200,300$, and $400 \mathrm{ng})$ of Notch1-IC expression vector. Cells were harvested $24 \mathrm{~h}$ after cotransfection. Luciferase activity driven by each p53-responsive promoter in the presence of p53 expression but in the absence of Notch1-IC expression was set to 100 units. In this and subsequent luciferase assays, results from at least three independent experiments are presented. (b) Effects of transiently expressed Notch1-IC on intracellular expression of p21, MDM2, and PUMA. HCT116 p53-1- cells $\left(2 \times 10^{6}\right)$ were cotransfected with p53 expression vector $(400 \mathrm{ng})$ and increasing amounts $(400,800,1,200$, and $1600 \mathrm{ng})$ of Notch1-IC expression vector. After incubation for $24 \mathrm{~h}$, whole-cell lysate was analyzed by immunoblotting for the expression of endogenous p21, MDM2, and PUMA. The cellular levels of $\alpha$-Tubulin or 14-3-3 $\varepsilon$ in cotransfected cells were also examined as internal controls. The endogenous levels of Notch downstream target gene HES were also monitored. (c) Northern blot of endogenous p21 mRNAs from UV-treated HCT116 $\mathrm{p53}^{+/+}$cells. Cells $\left(2 \times 10^{6}\right)$ were transfected with Notch1-IC expression vector $(500 \mathrm{and} 1000 \mathrm{ng})$ and were treated with $30 \mathrm{~J} / \mathrm{m}^{2} \mathrm{UV}$. After incubation for $8 \mathrm{~h}$, total RNAs were extracted and probed with DIG-labeled oligonucleotides specific for Notch 1 or $p 21$ gene. The band intensity of p21 in control cells, which were neither treated with UV nor transfected with Notch1-IC, was set to 1.00 unit. The relative band intensities of $p 21 \mathrm{mRNA}$ in Northern blot were determined by densitometric scanning of RNA bands using Quantity One software (Bio-Rad) and normalized by the amounts of 18S rRNA in each sample. The expression of transfected Notch1-IC was also examined by Northern blotting. Ribosomal RNAs were used as a loading control. (d) Effects of transiently expressed Notch1-IC on p53 transactivation in COS and HeLa cells. Cells $\left(2 \times 10^{5}\right)$ were cotransfected with p53 expression vector $(100 \mathrm{ng})$ and Notch1-IC expression vector (100 and $\left.400 \mathrm{ng}\right)$ together with luciferase reporter plasmids containing p53-responsive promoters

is important for the modulation of p53 transcriptional activity. The expression of the N-terminal fragment of Notch1-IC, which interacts with $\mathrm{p} 53$, results in the repression of p53 transactivation as well as the inhibition of p53 phosphorylation on Ser 15, 37, and 46 in cotransfected HCT116 $p 53^{-1-}$ cells (Figure $4 a$ and b). However, the 

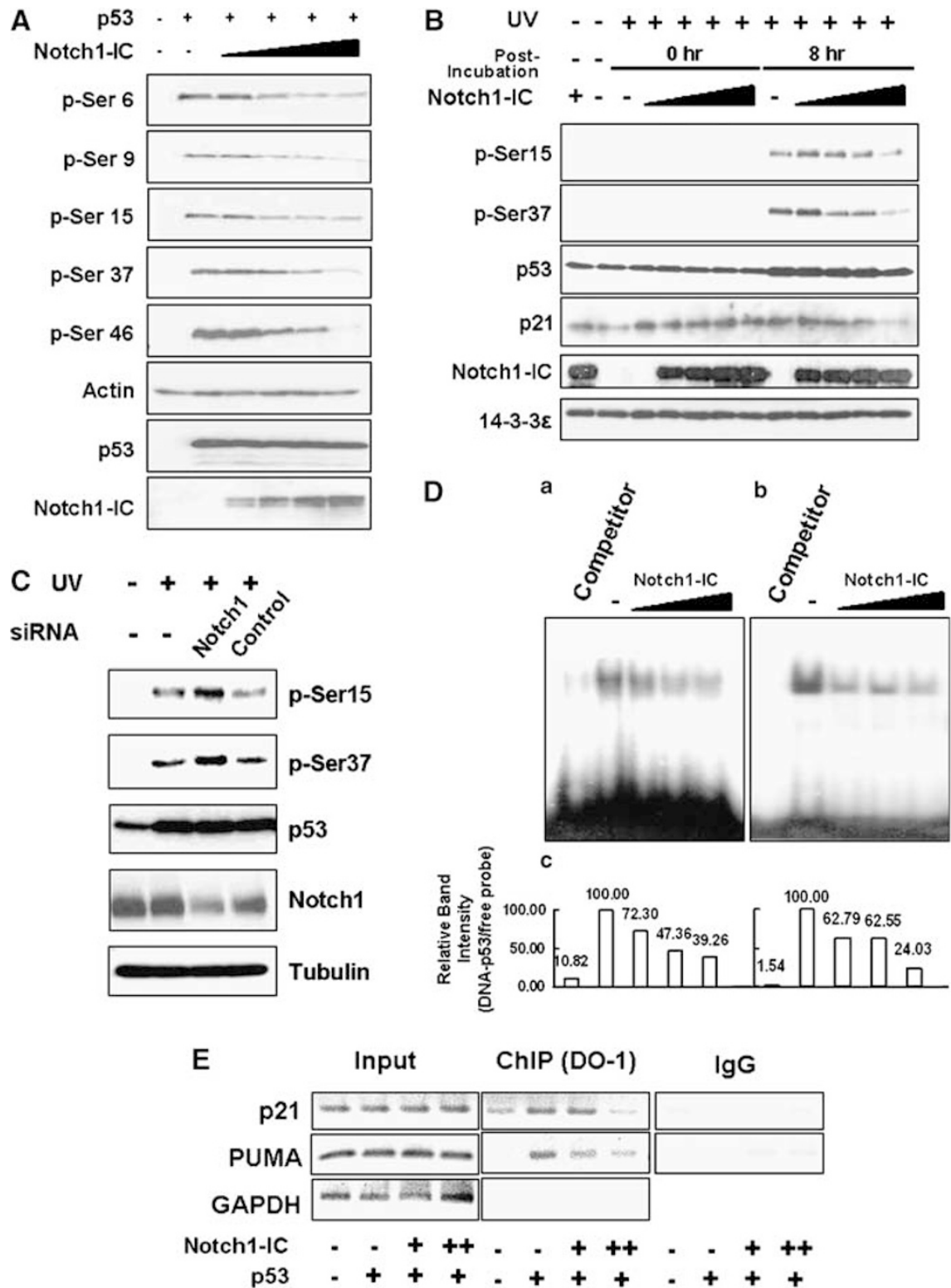

Figure 2 Notch signaling inhibits p53 phosphorylation and DNA binding. (A) HCT116 p53-- cells $\left(2 \times 10^{6}\right)$ were cotransfected with FLAG-tagged p53 expression plasmid $(400 \mathrm{ng})$ and increasing amounts $(400,800,1200$, and $1600 \mathrm{ng})$ of Notch1-IC expression vector. At $24 \mathrm{~h}$ after cotransfection, the phosphorylation of transiently expressed p53 on Ser residues was determined by immunoreactivity using antibodies that specifically recognize p53, phosphorylated at specific Ser residues. (B) HCT116 $p 53^{+1+}$ cells $\left(2 \times 10^{6}\right)$ were transfected with increasing amounts $(0.5,1,1.5$, and $2 \mu \mathrm{g})$ of Notch1-IC expression vector, incubated for $24 \mathrm{~h}$, and exposed to $30 \mathrm{~J} / \mathrm{m}^{2} \mathrm{UV}$. Ser phosphorylation of endogenous p53 was determined $8 \mathrm{~h}$ after UV irradiation. Control cells were transfected with $2 \mu \mathrm{g}$ of Notch1-IC expression vector alone. The levels of endogenous p21 and ectopically expressed Notch1-IC were also monitored. (C) HCT116 $p 53^{+/+}$cells treated with $0.13 \mu \mathrm{M}$ Notch1 siRNA or control siRNA for $24 \mathrm{~h}$ were exposed to $30 \mathrm{~J} / \mathrm{m}^{2} \mathrm{UV}$ and the phosphorylation of endogenous p53 on Ser residues was examined $8 \mathrm{~h}$ after UV irradiation. (D) Notch1-IC expression inhibits p53 DNA binding. HCT116 p53 ${ }^{-1-}$ cells $\left(2 \times 10^{6}\right)$ were cotransfected with p53 expression vector $(1 \mu \mathrm{g})$ and increasing amounts $(1,2$, and $4 \mu \mathrm{g})$ of Notch1-IC expression vector. Nuclear extracts were incubated with ${ }^{32} \mathrm{P}$-end-labeled 26 -mer double-stranded oligonucleotides containing either the p53-binding site from p21 promoter (a) or the p53-binding site from GADD45 promoter (b). Summary of EMSA data is shown. Relative band intensities of DNA-p53 complex in EMSA were determined by densitometric scanning using Quantity One software (Bio-Rad) and normalized by the amount of free probe. The relative band intensity of DNA-p53 protein complex from HCT $116 \mathrm{p53^{-1 } -}$ cells transfected with p53 alone was set to 100 units (c). (E) p53 binding to endogenous promoters of $p 21$ and PUMA was assessed by ChIP. HCT116 p53 $3^{+/+}$cells $\left(2 \times 10^{6}\right)$ were transfected with p53 expression vector ( $400 \mathrm{ng}$ ) together with Notch1-IC expression vector (400 or $1600 \mathrm{ng}$ ) and processed for ChIP with anti-p53 antibody (DO-1) or control lgG (Upstate Biotechnology). The immunoprecipitates were analyzed by PCR using the specific primer for p21 or PUMA promoter. The control PCR reactions were performed using the specific primer for GAPDH. The image of PCR products was presented in reversed black and white in which the DNA band is in black

expression of the C-terminal fragment of Notch1-IC, which lacks the ability to interact with p53, neither repressed p53 transactivation (Figure 4a) nor inhibited p53 phosphorylation (Figure 4b).
Notch transcriptional activity is not required to repress p53 transactivation. Experiments were conducted to determine whether transcriptional activity of Notch1 interferes with p53 transactivation function. The experiments 


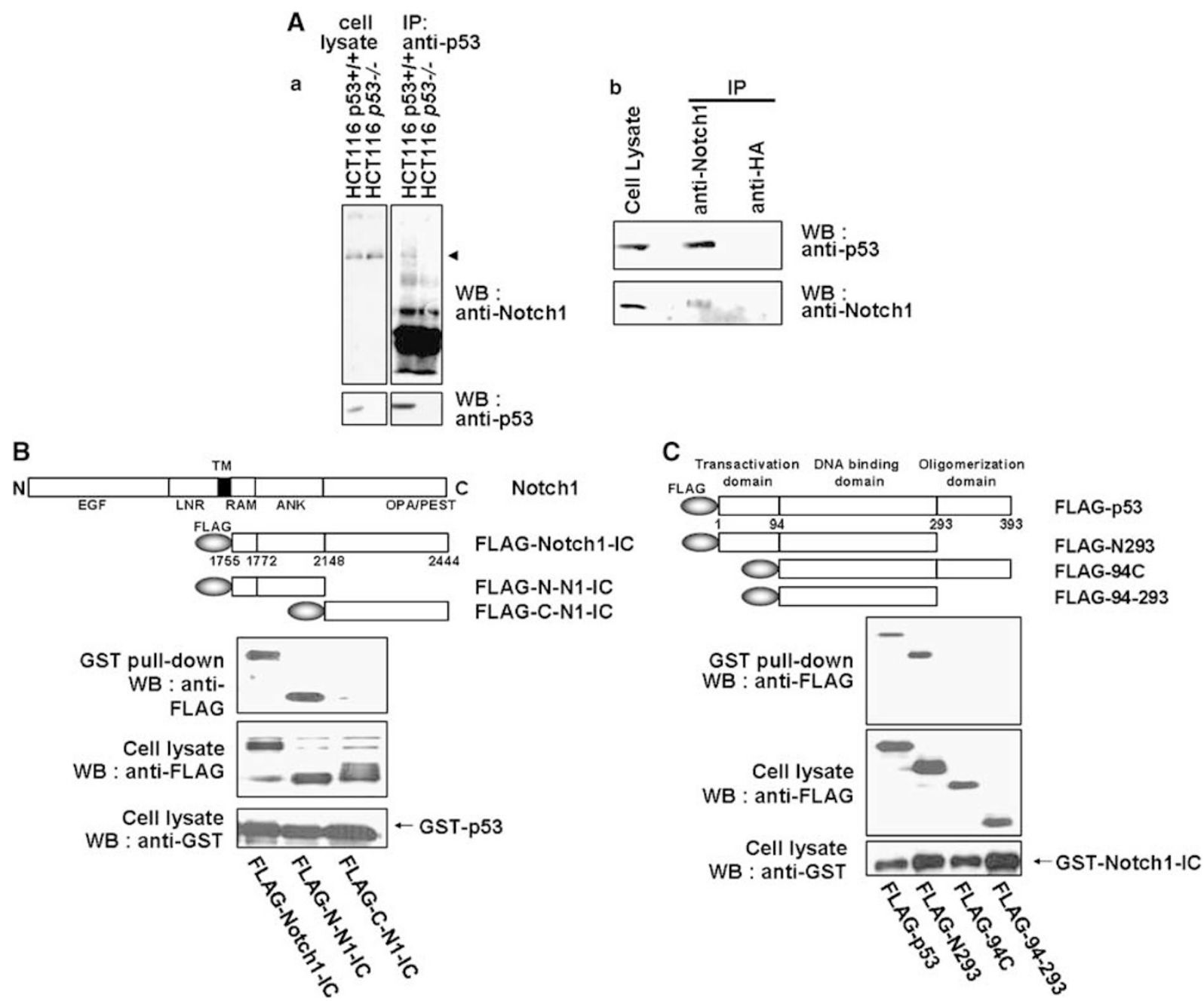

Figure 3 Notch1-IC interacts with p53. (A) (a) Notch1-IC interacts with p53 in HCT116 p53 ${ }^{+/+}$cells. Endogenous expression of Notch1-IC (upper left) and p53 (lower left) in HCT116 $p 53^{+/+}$or HCT116 $p 53^{-/-}$cells was examined by immunoblot analysis. Equal amounts of cell lysate protein from HCT116 $p 53^{+/+}$and HCT116 $p 53^{-/-}$ cells were immunoprecipitated with anti-p53 (C-19) antibody. The immune complexes were resolved by immunoblot analysis using an antibody directed against the N-terminal region of p53 (lower right) or Notch1 (upper right). The arrowhead indicates Notch1-IC associated with p53. (b) Equal amount of cell lysates from HCT116 p53 ${ }^{+/+}$cells were immunoprecipitated with anti-Notch1 antibody. The precipitates were resolved in SDS-PAGE and the associated proteins were analyzed by immunoblotting using anti-p53 or anti-Notch1 antibody. Anti-HA antibody was employed for the negative control experiment. (B) The N-terminal region of Notch1-IC interacts with p53. HCT116 p53 ${ }^{-1-}$ cells $\left(2 \times 10^{6}\right)$ were cotransfected with expression vector for FLAG-tagged Notch1-IC deletion derivatives $(1 \mu \mathrm{g})$ and GST-fused p53 $(1 \mu \mathrm{g})$. After incubation for $24 \mathrm{~h}, \mathrm{GST}$-fused p53 in cell lysates was purified by GST pull-down. The binding of FLAG-tagged Notch1-IC derivatives to GST-fused p53 was examined by SDS-PAGE and immunoblotting using anti-FLAG monoclonal antibody (top). The expression of FLAG-tagged Notch1-IC derivatives (middle) and GST-fused p53 (bottom) in cell lysates was verified. (C) The $\mathrm{N}$-terminal region of p53 interacts with Notch1-IC. HCT116 $p 53^{-1-}$ cells $\left(2 \times 10^{6}\right)$ were cotransfected with expression vector for GST-fused Notch1-IC (1 $\left.\mu \mathrm{g}\right)$ and FLAGtagged p53 derivatives $(1 \mu \mathrm{g})$. The binding of GST-fused Notch1-IC to FLAG-tagged p53 derivatives was determined

utilized $\triangle$ RAM-N1-IC mutant, a Notch1-IC deletion mutant lacking a RAM domain which interacts with CBF1 to activate Notch target genes such as HES1 and HES2. ${ }^{18,19}$ In accordance with previous reports, $\triangle$ RAM-N1-IC expression failed to transactivate luciferase reporter containing either $6 \times$ NRE (Notch Responsive Element) or HES promoter (Figure 5a). In contrast, both $\triangle$ RAM-N1-IC mutant and wildtype Notch1-IC reduced luciferase reporter activity driven by the promoters of the p53-responsive genes $p 21, m d m 2$, and bax (Figure 5b). Like wild-type Notch1-IC, the expression of $\triangle$ RAM-N1-IC inhibited the phosphorylation of endogenous p53 at Ser 15 and 37 in transfected cells treated with $30 \mathrm{~J} / \mathrm{m}^{2}$ UV (Figure 5c). Moreover, ectopically expressed $\triangle \mathrm{RAM}-\mathrm{N} 1$ IC was also capable of robust binding with p53 (Figure 5d).
Notch signaling downregulates p53-dependent apoptosis. In an effort to gain more insight into the biological function of Notch signaling in the regulation of p53-dependent pathways, apoptotic responses resulting from UV irradiation were evaluated. Expression of Notch1IC resulted in the relative resistance to UV-induced apoptosis, which is reportedly known as a p53-dependent cellular event. ${ }^{20}$ The negative role of Notch signaling on UV-induced apoptosis was further supported by the result showing the elevated level of apoptosis by Notch1 siRNA in UV-treated HCT116 $\mathrm{p53}^{+/+}$cells (Figure 6a). Notch1-IC expression also plays negative roles on caspase- 3 activation and PARP cleavage in UV-treated HCT116 $\mathrm{p53}^{+/+}$cells (Figure 6b). Like wild-type Notch1-IC, the expression of 
a
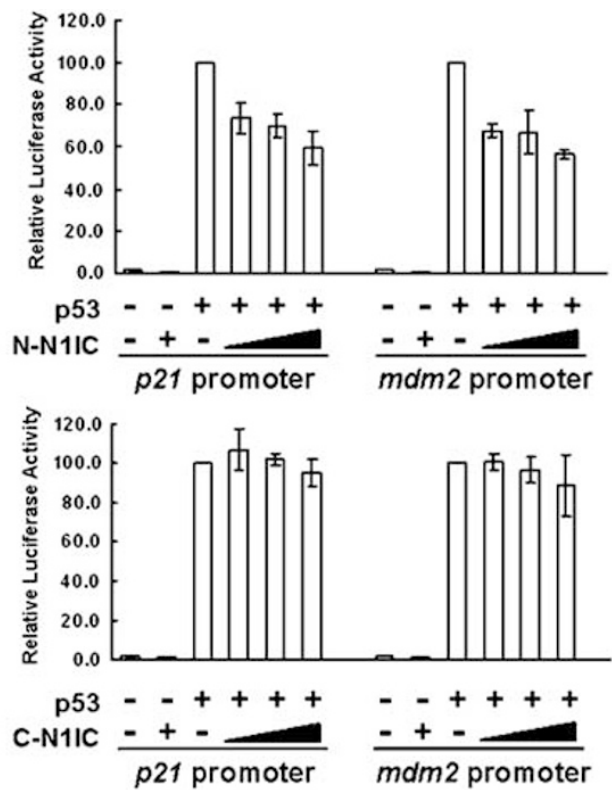

b
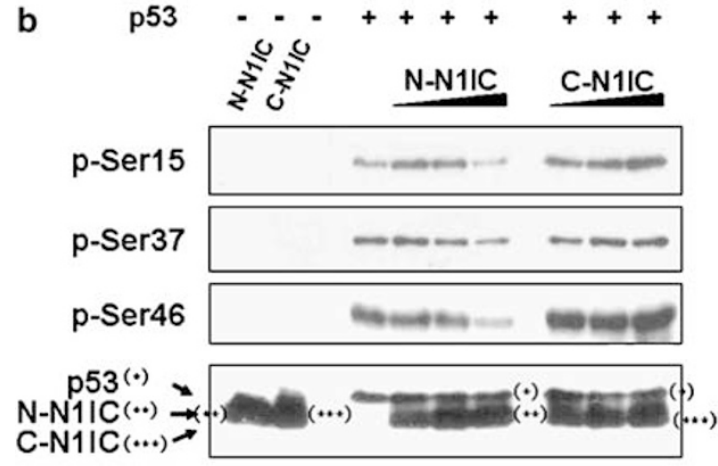

Tubulin

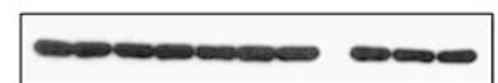

Figure 4 The N-terminal region of Notch1-IC is responsible for both the inhibition of p53 phosphorylation and transactivation. (a) HCT116 p53 ${ }^{-1-}$ cells $\left(2 \times 10^{5}\right)$ were cotransfected with plasmids for $p 53(100 \mathrm{ng})$ and luciferase reporter (100 ng) together with increasing amounts $(100,200,300$, and $400 \mathrm{ng})$ of the expression vector for the $\mathrm{N}$-terminal or $\mathrm{C}$-terminal fragment of Notch1-IC. After incubation for $24 \mathrm{~h}$, luciferase activity driven by p53-responsive promoter of $p 21$ or mdm2 was determined. (b) HCT116 p53 ${ }^{-1-}$ cells $\left(2 \times 10^{6}\right)$ were cotransfected with p53 expression vector ( $400 \mathrm{ng}$ ) and increasing amounts $(400,800$, and $1600 \mathrm{ng})$ of expression vector for the N-terminal or C-terminal fragment of Notch1-IC. After incubation for $24 \mathrm{~h}$, p53 phosphorylation was determined by immunoreactivity using antibodies against phosphorylated p53 on specific Ser residues. The level of intracellular $\alpha$-Tubulin was expressed as internal controls

$\triangle$ RAM-N1-IC, which is capable of interacting with p53, also inhibited caspase-3 activation (Figure 6c). In addition, Notch1 silencing by Notch1 siRNA transfection restored UV-induced apoptosis as evidenced by the increased PARP cleavage in UV-irradiated HCT116 $p 53^{+/+}$cells (Figure $6 \mathrm{~d}$ ).

\section{Discussion}

Previously, conflicting conclusions on the reciprocal relationship between Notch signaling and p53 function have been reported. First, p53 may negatively regulate Notch signaling.
The intracellular levels of Notch1-IC and its downstream target HES1 were elevated in $p 53^{-1-}$ mouse thymocytes as compared with $p 53^{+/+}$thymocytes. ${ }^{21}$ Evidence for the competition between p53 and Notch1-IC for binding to the coactivator p300 also supports the negative regulation of Notch signaling by $\mathrm{p} 53 .^{22}$ The common transcriptional coactivator p300 interacts with the EP domain of Notch1 through the $\mathrm{CH} 3$ region to enhance Notch1-mediated transactivation. p53 interferes with Notch1-mediated transactivation by competing for binding to $\mathrm{p} 300$. p53 was also shown to downregulate Notch1 activation by enhancing the transcription of $p 21$ whose expression represses the transcription of the gene for Presenilin1, which is necessary for Notch activation. ${ }^{23}$ Second, members of the tumor-suppressive p53 family may activate the Notch signaling pathway. p53 family members p63 and p73 upregulate transcription of Jag- 1 and Jag-2 genes, which encode Notch ligands. ${ }^{24}$ Third, Notch signaling may upregulate p53 transactivation. The expression of Notch1-IC elevated the levels of nuclear p53 and its target gene transcription in several mammalian cell lines including human hepatocellular carcinoma cells, mouse neural progenitor cells, and human cervical cancer cells. ${ }^{25-27}$ Increased p53 function by Notch signaling has also been demonstrated by an increase in p53-dependent apoptosis in cells expressing activated Notch $1 .{ }^{27}$ Fourth, Notch signaling may negatively regulate p53 function and inhibit apoptosis. Overexpression of activated Notch1 decreased p53 transcriptional activity and p53-dependent apoptosis in cultured mammalian cells ${ }^{28,29}$ and in mice. ${ }^{30}$ Suggested roles for Notch1 in the downregulation of p53 function involve the amplification of cell survival signals through $\mathrm{PI} 3 \mathrm{~K} / \mathrm{Akt} / \mathrm{PKB}$ pathway ${ }^{28,29}$ or ARF/ MDM2 pathway..$^{30}$

The present study supports the negative roles for Notch signaling in p53 function. We have shown that activated Notch1 interferes with p53 transactivation of downstream target genes (Figure 1). The protein stability and biochemical activity of p53 are tightly regulated by a variety of mechanisms. One mechanism likely to mediate both the stability and activity of p53 is phosphorylation. Kinases responsible for p53 phosphorylation have been identified, including casein kinase I and II, DNA-PK, ATM, ATR, CDK-activating kinase, cyclindependent kinases, and protein kinase $C .{ }^{31}$ Our data indicate that Notch signaling inhibited phosphorylation of various Ser residues in both ectopically expressed p53 (Figure 2A) and DNA damage-induced endogenous p53 (Figure 2B). Correspondingly, we found that inactivation of Notch signaling by Notch1 siRNA restores p53 phosphorylation at Ser 15 and 37 in UV-treated HCT116 p53 ${ }^{+/+}$cells (Figure $2 \mathrm{C}$ ). The function of p53 protein is largely regulated by its stability. p53 is normally maintained at low levels in unstressed mammalian cells by MDM2-induced p53 ubiquitination and subsequent degradation by $26 \mathrm{~S}$ proteasomes. When cells encounter stress such as DNA damage or oncogenic gene expression, p53 ubiquitination is suppressed, and p53 is stabilized in the nuclei in order to induce the expression of p53 target genes. ${ }^{31}$ Several studies highlight the importance of p53 phosphorylation to its stability. Phosphorylation of p53 on Ser 20 has been proposed to stabilize both ectopically expressed and endogenous p53 in cultured mammalian cells by weakening the interaction with MDM2. ${ }^{32,33} \mathrm{JNK}$-mediated phosphorylation of 
a

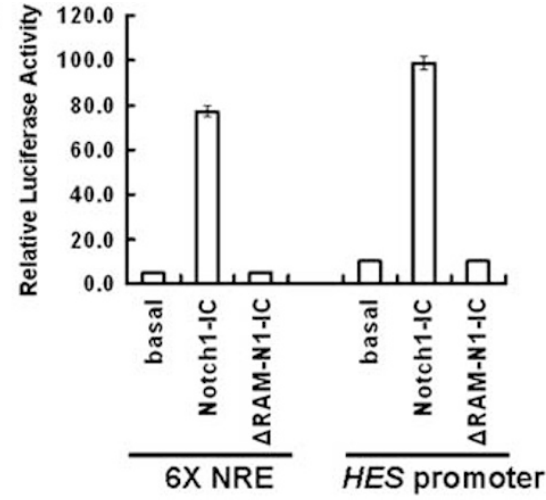

b
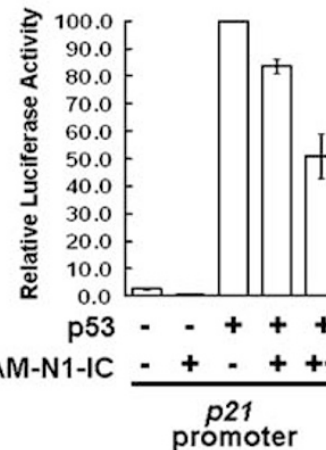

C

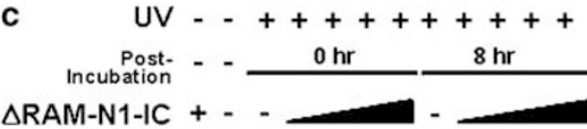

$\triangle R A M-N 1-$

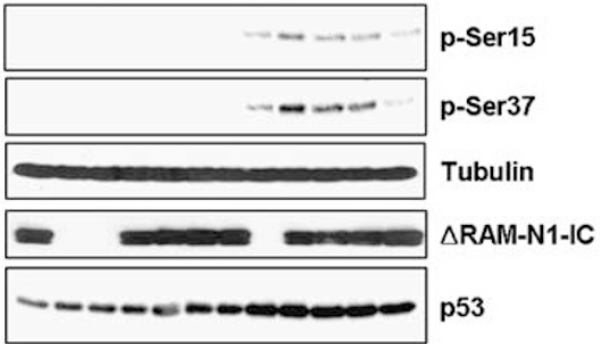

d
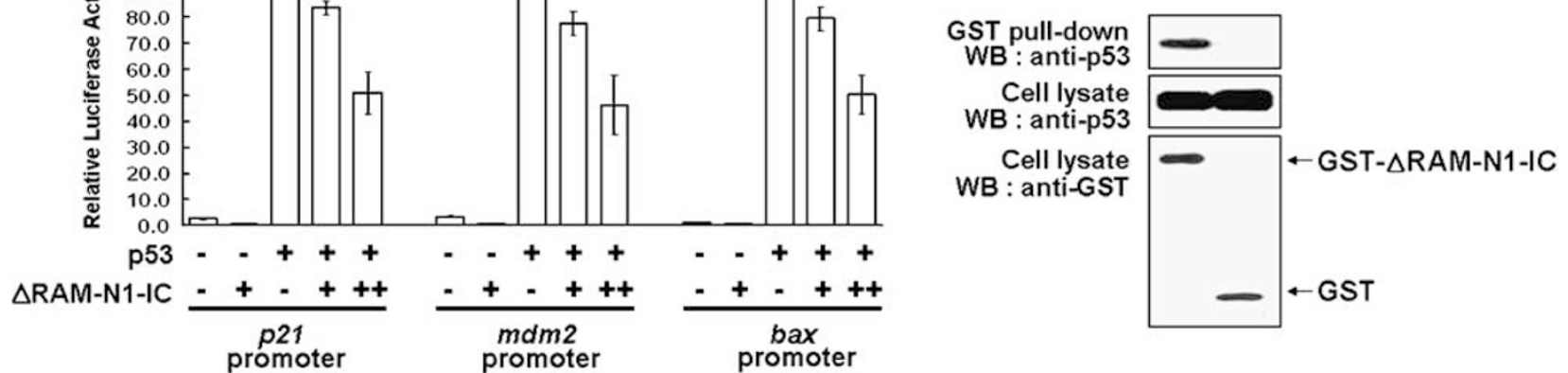

Figure 5 Notch1 transcriptional activity is dispensable for the repression of p53 transactivation. (a) HCT116 p53-- cells $\left(2 \times 10^{5}\right)$ were cotransfected with luciferase reporter plasmid $(100 \mathrm{ng}$ ) containing $6 \times$ NRE (Notch Response Element) and the expression vector for Notch1-IC or $\triangle$ RAM-N1-IC (100 ng each) (left). Luciferase activity driven by HES promoter in cotransfected cells was determined (right). (b) HCT116 p53 ${ }^{-l-}$ cells $\left(2 \times 10^{5}\right)$ were cotransfected with plasmids encoding $\triangle$ RAM-N1-IC (100 and $400 \mathrm{ng}$ ), p53 (100 ng), and luciferase reporter plasmid containing each p53-responsive promoter $(100 \mathrm{ng})$. (c) HCT116 p53 ${ }^{+1+}$ cells $\left(2 \times 10^{6}\right)$ were transfected with increasing amounts $(0.5,1,1.5$, and $2 \mu \mathrm{g})$ of plasmid encoding $\triangle$ RAM-N1-IC. At $24 \mathrm{~h}$ after transfection, cells were irradiated with $30 \mathrm{~J} / \mathrm{m}^{2} \mathrm{UV}$. After additional incubation for $8 \mathrm{~h}$, the phosphorylation of endogenous p53 in transfected cells was examined as in Figure 2B. (d) The interaction between GST-fused $\triangle$ RAM-N1-IC and ectopically expressed p53 was examined in cotransfected HCT116 p53 ${ }^{-1-}$ cells

p53 on Thr 81 was also shown to increase p53 stability and transcriptional activity in cultured human cells. ${ }^{34}$ However, the present study does not support the biochemical mechanism for Notch-mediated repression of p53 transactivation by reduced p53 stability. We investigated the effects of Notch signaling on p53 stability but did not observe any differences in p53 levels in the presence or absence of Notch1-IC expression (Figures $1 \mathrm{~b}, 2 \mathrm{~A}-\mathrm{C}$, and $6 \mathrm{~b}$ ). A recent study has proposed that Notch suppresses tumor-suppressive p53 function through ARF/MDM2-dependent proteolytic degradation of $p 53$ based on the almost undetectable levels of p53 and a lack of the MDM2 inhibitor ARF protein in transgenic mice that express human Notch1-IC under the transcriptional control of the tetracycline operator sequences. ${ }^{30}$ However, HCT116 human colon cancer cells do not express functional ARF protein. ${ }^{35}$ Therefore, it is unlikely that Notch1 signaling interferes with the expression of ARF which promotes MDM2 degradation and elevates cellular levels of p53 by increasing its stability. A more recent report in the literature has demonstrated the inhibition of p53 phosphorylation and its transactivation by Notch1-IC in human cancer cells and proposed a biochemical mechanism in which activated Notch1 downregulates p53-dependent transactivation and p53-induced apoptosis by the aspects of PI3K/Akt/PKB pathway, ${ }^{29}$ but we failed to prove this conclusion in our studies. Our results showed that the inhibition of PI3K, which signals cell survival through $\mathrm{PKB} / \mathrm{Akt}$ pathway, did not affect Notch1-mediated downregulation of p53 transactivation in HCT116 $p 53^{+/+}$cells (data not shown). While the precise biochemical mechanism remains exclusive, our results propose that the expression of activated Notch1 interferes with p53 binding to the promoters of its target genes (Figure $2 \mathrm{D}$ and $\mathrm{E})$, leading to the downregulation of p53-dependent transactivation.

Previous reports have identified several ankyrin repeat proteins such as 53BP1 and 53BP2 that contain ankyrin repeats and bind to $p 53$. These proteins are also known to regulate the tumor suppressor function of $p 53 .{ }^{36}$ We were interested to know whether Notch protein containing six ankyrin repeats interacts with $\mathrm{p} 53$ and confirmed the intracellular association of Notch with p53 (Figure 3). Immunofluorescence analysis using confocal microscope reveals that $\mathrm{p} 53$ colocalizes with Notch1-IC in the nucleus of cotransfected HCT116 p53 ${ }^{-1-}$ cells (data not shown). This rules out the possibility that Notch1 may repress the p53 function by altering the subcellular distribution of p53 in HCT116 cells. This physical interaction between Notch1-IC and p53 seems to provide a functional framework for the inhibition of p53 phosphorylation and transactivation by Notch signaling. Overexpression of the $\mathrm{N}$-terminal fragment of Notch1-IC, which is capable of interacting with p53, inhibited both p53 phosphorylation and its transcriptional activity. In 
b<smiles>[O]</smiles>

UV<smiles>CCC(C)C</smiles><smiles>CCCCC</smiles><smiles>CCCCC</smiles>
$\stackrel{1.6}{\longmapsto}$

Notch SiRNA Control siRNA p53$$
+
$$

$+$

$-1-$

$$
+
$$
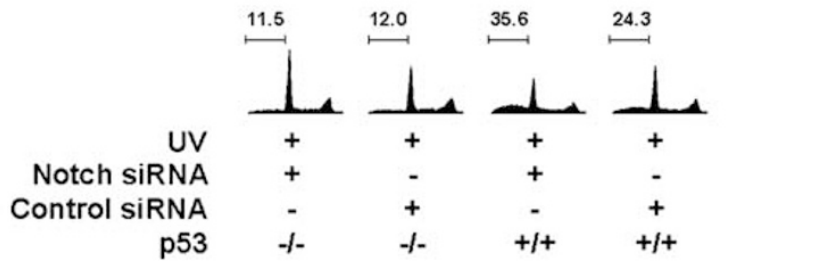

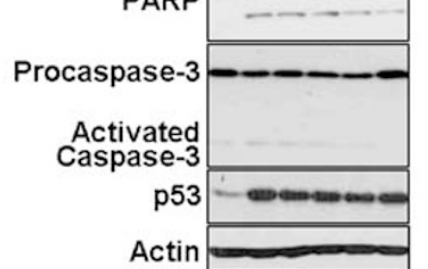

C

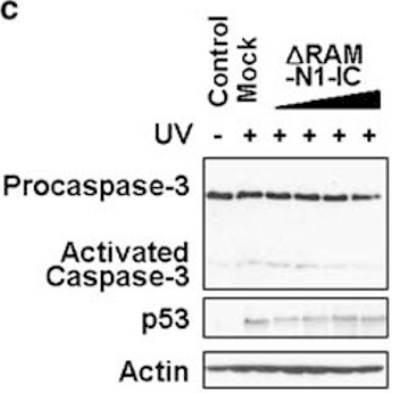

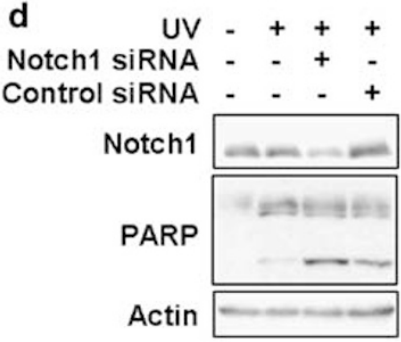

Figure 6 Notch1-IC inhibits UV-induced apoptosis. (a) HCT116 $p 53^{+/+}$cells $\left(2 \times 10^{6}\right)$ were transfected with $2 \mu \mathrm{g}$ of Notch1-IC expression vector. Transfected cells were irradiated with $80 \mathrm{~J} / \mathrm{m}^{2} \mathrm{UV}$. Irradiated cells were postincubated for $24 \mathrm{~h}$, harvested, and stained with PI followed by ethanol fixation. DNA contents were measured by FACS. The DNA contents of cells at sub-G1 were used as the index for the degree of apoptosis (upper). HCT116 $p 53^{+/+}$or $p 53^{-1-}$ cells were transfected with $0.13 \mu \mathrm{M}$ of Notch1 siRNA or control siRNA. At $24 \mathrm{~h}$ after transfection, cells were irradiated with $30 \mathrm{~J} / \mathrm{m}^{2} \mathrm{UV}$ treatment, postincubated for $24 \mathrm{~h}$, harvested, stained with PI and analyzed for apoptosis by FACS (lower). (b) The effect of Notch1-IC on the cleavage of procaspase-3 and PARP in $30 \mathrm{~J} / \mathrm{m}^{2} \mathrm{UV}$-treated HCT116 p53 ${ }^{+1+}$ cells was examined. HCT116 $p 53^{+1+}$ cells $\left(2 \times 10^{6}\right)$ were transfected with increasing amounts $(500,1000,1500$, and $2000 \mathrm{ng})$ of Notch1-IC expression vector. Transfected cells were irradiated with $30 \mathrm{~J} /$ $\mathrm{m}^{2}$ UV. The proteolytic cleavage of procaspase-3 or PARP was examined by SDS-PAGE and immunoblot analysis using anti-PARP or anti-caspase-3 antibody. (c) The effect of $\triangle$ RAM-N1-IC on UV-induced apoptosis was assessed by the cleavage of procaspase-3. HCT116 p53 $3^{+/+}$cells $\left(2 \times 10^{6}\right)$ were transfected with varying amounts $(500$, 1000,1500 , and $2000 \mathrm{ng}$ ) of expression vector for $\triangle$ RAM-N1-IC. Proteolytic cleavage of procaspase-3 was examined by immunoblot analysis using anti-caspase-3 antibody. (d) siRNA-induced knockdown of Notch1 abrogates the inhibitory effects of Notch1-IC on PARP cleavage in UV-treated HCT116 p53 ${ }^{+/+}$cells. Cells were transfected with Notch1 siRNA or control siRNA. After incubation for $24 \mathrm{~h}$, cells were irradiated with $30 \mathrm{~J} / \mathrm{m}^{2} \mathrm{UV}$ and incubated for additional $24 \mathrm{~h}$. The cleavage of PARP was analyzed by immunoblot analysis using anti-PARP antibody

contrast, the C-terminal fragment of Notch1-IC, which lacks the ability to interact with p53, failed to inhibit p53 phosphorylation and its transactivation (Figure 4). Whether or not the interaction between Notch1-IC and p53 plays an essential function in Notch-mediated repression of p53 transactivation still remains to be established. However, it is unlikely that the binding of Notch $1-\mathrm{IC}$ to $\mathrm{p} 53$ directly hinders the binding of p53 to its recognition sites of DNA and represses p53 transactivation. As the central DNA-binding domain of p53 (amino acids 94-293) lacks the ability to interact with Notch1-IC. Notch1-IC bound to the $\mathrm{N}$-terminal domain of p53 might not be directly responsible for the inhibition of the binding of central p53 DNA-binding domain to DNA. It is noteworthy that posttranslational modifications such as phosphorylation and acetylation have been implicated in the regulation of p53 sequence-specific DNA binding. ${ }^{31}$ In addition, there are studies suggesting that the C-terminal domains of p53 could indirectly influence the sequence-specific p53 DNA binding. ${ }^{37,38}$

The results in Figure 5 rule out the possibility that Notch signaling modulates p53 transactivation function through Notch target genes. HES family proteins are transcriptional repressors that act as Notch effectors by negatively regulating the expression of downstream genes such as tissue-specific transcription factors that induce neuronal differentiation. ${ }^{4}$
Expression of $\triangle$ RAM-N1-IC mutant lacking the RAM domain, which is the main CSL interaction site, failed to activate HES-1 promoter linked to luciferase reporter in transfected HCT116 $\mathrm{p53}^{-1-}$ cells (Figure 5a). Nonetheless, $\triangle$ RAM-N1-IC, which lacks Notch1 transcriptional activity, repressed p53-dependent transactivation as much as wild-type Notch1-IC (Figure $5 b$ ). Moreover, overexpression of $\triangle$ RAM-N1-IC also inhibited endogenous p53 phosphorylation at Ser 15 and 37 in UV-treated HCT116 $p 53^{+/+}$cells (Figure 5c). Both wild-type Notch1-IC and $\triangle$ RAM-N1-IC deletion mutant were capable of binding to p53 (Figure $5 d$ ). These results support our interpretation that physical interaction between activated Notch1 and p53 is important for both the inhibition of p53 phosphorylation and repression of its transactivation by Notch signaling.

Previous studies have defined the antiapoptotic role of Notch signaling in both animal ${ }^{30,39}$ and cultured in vitro cell models. ${ }^{28,29}$ Our results in Figure 6 suggest that the negative impact of Notch signaling on p53-dependent apoptosis correlates with decreased activation of caspase-3 and reduced PARP cleavage. Although the precise mechanism by which the physical interaction between p53 and activated Notch modulates p53 function remains to be elucidated, our findings offer an alternative role for Notch signaling in counteracting p53 tumor suppressor activity during tumorigenesis. 


\section{Materials and Methods}

Cells and antibodies. Human colon cancer HCT116 $p 53^{+/+}$and HCT116 $p 53^{-1-}$ cells grown in DMEM supplemented with $10 \%$ FBS (Gibco BRL) were transfected using Lipofectamine Plus reagent (Invitrogen) as specified by the manufacturer. Antibodies against PUMA, caspase-3, and PARP, and phosphospecific antibodies that recognize phosphorylated p53 on each Ser residue were purchased from Cell Signaling. Antibodies against FLAG, GST, MDM2, $\alpha$-Tubulin, and $\beta$-Actin were supplied by Sigma. Antibodies directed against $\mathrm{C}$-terminal Notch1, p21, HES1, HA, N-terminal p53 (Bp53-12 and DO-1), C-terminal p53 (C$19)$, and 14-3-3e were from Santa Cruz. FITC-conjugated anti-CD20 antibody was from Becton Dickinson.

Plasmids. cDNAs encoding full-length human p53 (amino acids 1 - STOP) and p53 fragments N293 (amino acids 1-293), 94C (amino acids 94 - STOP), and 94293 (amino acids 94-293) were cloned in-frame to Kpnl and BamHI sites of pFLAGCMV-2 vector (Sigma) to generate FLAG-tagged p53 constructs. cDNAs encoding full-length human Notch1-IC (amino acids 1762 - STOP) and Notch1-IC deletion mutants N-N1-IC (amino acids 1762 - 2148), C-N1-IC (amino acids 2147 - STOP), and $\triangle$ RAM-N1-IC (amino acids 1877 - STOP) were cloned in-frame to Hindlll and BamHI sites of pFLAG-CMV-2 vector (Sigma) to generate FLAG-tagged Notch1-IC constructs. CDNAs encoding Notch1-IC and p53 were cloned into BamHI and Notl sites of mammalian GST fusion vector, $\mathrm{pEBG}$, to generate expression vectors for GST-Notch1-IC and GST-p53. $\triangle R A M-N 1-I C$ was cloned into BamHI and Clal sites of pEBG to produce GST- $\triangle$ RAM-N1-IC.

Luciferase assay. For the p53 reporter assay, cells seeded on a 12-well plate $\left(2 \times 10^{5} \mathrm{cells} /\right.$ well) were transfected with p53-responsive reporter gene construct $(100 \mathrm{ng})$ driven by a synthetic p53 responsive element or one of the promoters of p21, mdm2, or bax with or without p53 expression vector $(100 \mathrm{ng})$, together with increasing amounts of plasmid encoding Notch1-IC, $\triangle$ RAM-N1-IC, N-N1-IC, or CN1-IC. For the Notch1 reporter assay, HCT116 $p 53^{-1-}$ cells were cotransfected with a reporter plasmid containing either $6 \times$ NRE (Notch Response Element) or HES promoter together with plasmid for each Notch1 construct. Luciferase activity was assayed $24 \mathrm{~h}$ after transfection using Luciferase Assay System (Promega). The values of luciferase activity were normalized for transfection efficiencies by measuring $\beta$-galactosidase activities using Luminescent $\beta$-galactosidase detection kit II (Clontech).

Coimmunoprecipitation. HCT116 $p 53^{+/+}$and HCT116 $p 53^{-/-}$cells were grown in $100 \mathrm{~mm}$ dishes and lysed in a lysis buffer containing $50 \mathrm{mM}$ Tris- $\mathrm{HCl}(\mathrm{pH}$ 7.5), $120 \mathrm{mM} \mathrm{NaCl}, 0.5 \%$ Nonidet P- $40,50 \mathrm{mM} \mathrm{NaF}, 200 \mathrm{mM}$ sodium orthovanadate, and $1 \mathrm{mM}$ phenylmethylsulfonyl fluoride. Equal amounts of protein lysate were mixed with the antibody recognizing C-terminal p53 (C-19) or $\mathrm{C}$-terminal Notch1. After incubation for $16 \mathrm{~h}$ at $4^{\circ} \mathrm{C}, 50 \mu \mathrm{l} 50 \%$ Protein G Sepharose (Amersham Biosciences) was added and mixed at $4^{\circ} \mathrm{C}$ for an additional $2 \mathrm{~h}$. The bound proteins were washed six times with phosphate-buffered saline (PBS) and analyzed by $12 \%$ SDS-PAGE followed by immunoblotting using antibodies directed against C-terminal Notch1 or N-terminal p53 (Bp53-12).

GST pull-down assay. HCT116 $p 53^{-1-}$ cells $\left(2 \times 10^{6}\right)$ were transfected with $2 \mu \mathrm{g}$ total plasmid DNA. After incubation for $24 \mathrm{~h}$, transfected cells were lysed in the lysis buffer described above. Cell lysates were mixed with Glutathione-Sepharose 4B beads (Amersham-Pharmacia) by rocking at $4^{\circ} \mathrm{C}$ for $16 \mathrm{~h}$. The bound proteins were washed three times with PBS containing $500 \mathrm{mM} \mathrm{NaCl}$ and three times with PBS. The proteins bound to GST fusion proteins were analyzed by $10 \%$ SDS-PAGE followed by immunoblotting using antibodies directed against the respective epitopes.

EMSA. An aliquot $(30 \mu \mathrm{l})$ of reaction mixture containing $10 \mu \mathrm{g}$ nuclear proteins, $10 \mathrm{mM}$ HEPES (pH 7.5), $50 \mathrm{mM} \mathrm{KCl}, 0.5 \mathrm{mM}$ EDTA, $0.2 \mathrm{mM} \mathrm{BSA}, 1 \mathrm{mM}$ DTT, $10 \%$ glycerol, $3 \mu \mathrm{g}$ poly (dl-dC), and approximately $0.5 \mathrm{ng}$ of ${ }^{32} \mathrm{P}$-labeled DNA probe was incubated for $30 \mathrm{~min}$ at room temperature. The oligonucleotides used to probe p53 DNA-binding sites had the following sequences: $5^{\prime}$-AGC TTA GGC ATG TCT AGG CAT GTC TA-3' from $p 21$ promoter and $5^{\prime}$-TAG AGC GAA CAT GTC TAA GCA TGC TGG CGT CG-3' from GADD45 promoter. The oligonucleotides were annealed with their complementary strands and end-labeled with $\left[\gamma^{32}\right.$ P]ATP using T4 polynucleotide kinase. The reaction mixture was then subjected to electrophoresis in $0.5 \times$ TBE buffer $(1 \times$ TBE: $89 \mathrm{mM}$ Tris base, $89 \mathrm{mM}$ boric acid, and $2 \mathrm{mM} \mathrm{EDTA}$ ) on a $5 \%$ native polyacrylamide gel at $120 \mathrm{~V}$. Gels were dried and DNA-protein complexes were visualized by autoradiography.
ChIP. ChIP experiments were carried out as described ${ }^{40}$ Briefly, chromatin from HCT116 p53 $3^{+1+}$ cells overexpressing p53 and Notch1-IC was crosslinked using $1 \%$ formaldehyde for $10 \mathrm{~min}$ at $37^{\circ} \mathrm{C}$. After phenol-chloroform extraction and ethanol precipitation, the DNAs recovered from the immunocomplex and input material were PCR-amplified using primers designed to amplify the p53-binding site in p21 gene (forward primer: $5^{\prime}$-GTG GCT CTG ATT GGC TTT CTG-3', reverse primer: $5^{\prime}$-CTG AAA ACA GGC AGC CCA AG-3') or PUMA gene (forward primer: $5^{\prime}$-CTG TGG CCT TGT GTC TGT GAG TAC-3', reverse primer: $5^{\prime}$-CCT AGC CCA AGG CAA GGA GGA C-3'). PCR was also performed using primers for GAPDH gene (forward primer: $5^{\prime}$-TAC TAG CGG TTT TAC GGG CG-3', reverse primer: $5^{\prime}$ TCG AAC AGG AGG AGC AGA GAG CGA-3') as an internal control experiment.

Northern blot analysis. HCT116 $p 53^{+/+}$cells $\left(2 \times 10^{6}\right)$ were transfected with Notch1-IC expression vector (500 and $1000 \mathrm{ng}$ ). After incubation for $24 \mathrm{~h}$ transfected cells were treated with $30 \mathrm{~J} / \mathrm{m}^{2} \mathrm{UV}$ and harvested after postincubation for $8 \mathrm{~h}$. Total RNAs were extracted using Trizol Reagent (Molecular Research Center, Inc.) according to the manufacturer's protocol. RNA samples (10 $\mu \mathrm{g}$ each) were fractioned on a 1.2\% agarose-formaldehyde gel, and transferred to a positively charged nylon membrane. Specific primer for Notch1 gene (forward oligonucleotide: 5'-AGC TCT GGT TCC CTG AGG GCT T-3', reverse oligonucleotide: 5'-ATG CAG TCG GCG TCA ACC TCA C-3') or p21 gene (forward oligonucleotide: $5^{\prime}$-GTG TGA GCA GCR GCC GAA GT-3', reverse oligonucleotide: $5^{\prime}$-TTT TCG ACC CTG AGA GTC TCC A-3') was used for PCR. Whole-cell RNA was hybridized with DIG-labeled probes and assayed according to the manufacturer's protocol at $50^{\circ} \mathrm{C}$ for $12 \mathrm{~h}$ (Roche).

RNA interference. HCT116 $p 53^{+/+}$cells were transfected with $0.13 \mu \mathrm{M}$ Notch1 siRNA or control siRNA (Santa Cruz) using Oligofectamine (Invitrogen) as described by the manufacturer's instruction. Experiments were carried out $24 \mathrm{~h}$ after siRNA transfection.

Apoptosis assay. HCT116 $p 53^{+1+}$ cells $\left(2 \times 10^{6}\right)$ were transfected with Notch1-IC expression vector $(2 \mu \mathrm{g})$ together with expression vector for CD20 $(200 \mathrm{ng})$, a marker of transfected cells. After incubation for $24 \mathrm{~h}$, cells were treated with specified doses of UV, postincubated for $24 \mathrm{~h}$, harvested and mixed with FITCconjugated anti-CD20 antibody (Beckton Dickinson) and incubated for $20 \mathrm{~min}$ on ice. Cells were then fixed with ice-cold $70 \%$ ethanol and incubated on ice for $30 \mathrm{~min}$. The effect of Notch silencing on UV-induced apoptosis was carried out using Notch1 siRNA. Cells were transfected with Notch siRNA or control siRNA and incubated for $24 \mathrm{~h}$. Cells were irradiated with $30 \mathrm{~J} / \mathrm{m}^{2} \mathrm{UV}$. Cells were incubated for additional $24 \mathrm{~h}$ and harvested. Fixed cells were treated with RNasel and stained with $10 \mu \mathrm{g} / \mathrm{ml}$ propidium iodide (PI). DNA contents were determined by FACS. Cells with DNA content at sub-G0/G1 phase were considered as apoptotic cells. Apoptotic cell death was also examined by monitoring the proteolytic cleavage of PARP and procaspase-3. The immunoblot analysis was carried out using antibodies against each protein.

Acknowledgements. We are grateful to Dr. J Aster (Bringham and Women's Hospital, USA) for providing pcDNA3-Notch1-IC expression plasmid. This study was supported in part by grants from the Korean National Cancer Control Program, Ministry of Health and Welfare (0220150-3); the Korea Science and Engineering Foundation (2004-01885); and the Korea Research Foundation (KRF-2003-015C00534 and KRF-2005-070-C00105).

1. Kimble J, Henderson S, Crittenden S (1998) Notch/LIN-12 signaling: transduction by regulated protein slicing. Trends Biochem Sci 23: 353-357

2. Radtke F, Raj K (2003) The role of Notch in tumorigenesis: oncogene or tumour suppressor? Nat Rev Cancer 3: 756-767.

3. Lai EC (2002) Keeping a good pathway down: transcriptional repression of Notch pathway target genes by CSL proteins. EMBO Rep 3: 840-845.

4. Bailey AM, Posakony JW (1995) Suppressor of hairless directly activates transcription of enhancer of split complex genes in response to Notch receptor activity. Genes Dev 9 : 2609-2622.

5. Rangarajan A, Talora C, Okuyama R, Nicolas M, Mammucari C, Oh H et al. (2001) Notch signaling is a direct determinant of keratinocyte growth arrest and entry into differentiation. EMBO J 20: 3427-3436. 
6. Ellisen LW, Bird J, West DC, Soreng AL, Reynolds TC, Smith SD et al. (1991) TAN-1, the human homolog of the Drosophila notch gene, is broken by chromosomal translocations in T lymphoblastic neoplasms. Cell 66: 649-661.

7. Reynolds TC, Smith SD, Sklar J (1987) Analysis of DNA surrounding the breakpoints of chromosomal translocations involving the beta $\mathrm{T}$ cell receptor gene in human lymphoblastic neoplasms. Cell 50: 107-117.

8. Girard L, Hanna Z, Beaulieu N, Hoemann CD, Simard C, Kozak CA et al. (1996) Frequen provirus insertional mutagenesis of Notch1 in thymomas of MMTVD/myc transgenic mice suggests a collaboration of c-myc and Notch1 for oncogenesis. Genes Dev 10: 1930-1944.

9. Capobianco AJ, Zagouras P, Blaumueller CM, Artavanis-Tsakonas S, Bishop JM (1997) Neoplastic transformation by truncated alleles of human NOTCH1/TAN1 and NOTCH2. Mol Cell Biol 17: 6265-6273.

10. Jhappan C, Gallahan D, Stahle C, Chu E, Smith GH, Merlino G et al. (1992) Expression of an activated Notch-related int-3 transgene interferes with cell differentiation and induces neoplastic transformation in mammary and salivary glands. Genes Dev 6: 345-355.

11. Weijzen S, Rizzo P, Braid M, Vaishnav R, Jonkheer SM, Zlobin A et al. (2002) Activation of Notch-1 signaling maintains the neoplastic phenotype in human Ras-transformed cells. Nat Med 8: 979-986.

12. Zagouras P, Stifani S, Blaumueller CM, Carcangiu ML, Artavanis-Tsakonas S (1995) Alterations in Notch signaling in neoplastic lesions of the human cervix. Proc Natl Acad Sci USA 92: $6414-6418$

13. Nicolas M, Wolfer A, Raj K, Kummer JA, Mill P, van Noort M et al. (2003) Notch1 functions as a tumor suppressor in mouse skin. Nat Genet 33: 416-421.

14. Shou J, Ross S, Koeppen H, de Sauvage FJ, Gao WQ (2001) Dynamics of notch expression during murine prostate development and tumorigenesis. Cancer Res 61: 7291-7297.

15. Hanahan D, Weinberg RA (2000) The hallmarks of cancer. Cell 100: 57-70.

16. el-Deiry WS, Tokino T, Velculescu VE, Levy DB, Parsons R, Trent JM et al. (1993) WAF1, a potential mediator of p53 tumor suppression. Cell 75: 817-825.

17. Miyashita T, Reed JC (1995) Tumor suppressor p53 is a direct transcriptional activator of the human bax gene. Cell 80: 293-299.

18. Nam Y, Weng AP, Aster JC, Blacklow SC (2003) Structural requirements for assembly of the CSL.intracellular Notch1.Mastermind-like 1 transcriptional activation complex. J Biol Chem 278: 21232-21239

19. Roehl H, Bosenberg M, Blelloch R, Kimble J (1996) Roles of the RAM and ANK domains in signaling by the $C$. elegans GLP-1 receptor. EMBO J 15: 7002-7012.

20. Chao C, Saito S, Kang J, Anderson CW, Appella E, Xu Y (2000) p53 transcriptional activity is essential for p53-dependent apoptosis following DNA damage. EMBO J 19: 4967-4975.

21. Laws AM, Osborne BA (2004) p53 regulates thymic Notch1 activation. Eur J Immuno/ 34 726-734.

22. Oswald F, Tauber B, Dobner T, Bourteele S, Kostezka U, Adler G et al. (2001) p300 acts as a transcriptional coactivator for mammalian Notch-1. Mol Cell Biol 21: 7761-7774.

23. Roperch JP, Alvaro V, Prieur S, Tuynder M, Nemani M, Lethrosne F et al. (1998) Inhibition of presenilin 1 expression is promoted by $\mathrm{p} 53$ and p21WAF-1 and results in apoptosis and tumor suppression. Nat Med 4: 835-838.
24. Sasaki Y, Ishida S, Morimoto I, Yamashita T, Kojima T, Kihara C et al. (2002) The p53 family member genes are involved in the Notch signal pathway. J Biol Chem 277: 719-724.

25. Qi R, An H, Yu Y, Zhang M, Liu S, Xu H et al. (2003) Notch1 signaling inhibits growth of human hepatocellular carcinoma through induction of cell cycle arrest and apoptosis. Cancer Res 63: 8323-8329.

26. Talora C, Cialfi S, Segatto O, Morrone S, Kim Choi J, Frati L et al. (2005) Constitutively active Notch1 induces growth arrest of HPV-positive cervical cancer cells via separate signaling pathways. Exp Cell Res 305: 343-354.

27. Yang X, Klein R, Tian X, Cheng HT, Kopan R, Shen J (2004) Notch activation induces apoptosis in neural progenitor cells through a p53-dependent pathway. Dev Biol 269: $81-94$

28. Nair P, Somasundaram K, Krishna S (2003) Activated Notch1 inhibits p53-induced apoptosis and sustains transformation by human papillomavirus type 16 E6 and E7 oncogenes through a PI3K-PKB/Akt-dependent pathway. J Virol 77: 7106-7112.

29. Mungamuri SK, Yang X, Thor AD, Somasundaram K (2006) Survival signaling by Notch1: mammalian target of rapamycin (mTOR)-dependent inhibition of p53. Cancer Res 66: 4715-4724.

30. Beverly LJ, Felsher DW, Capobianco AJ (2005) Suppression of p53 by Notch in lymphomagenesis: implications for initiation and regression. Cancer Res 65: 7159-7168.

31. Bode AM, Dong Z (2004) Post-translational modification of p53 in tumorigenesis. Nat Rev Cancer 4: 793-805.

32. Chehab NH, Malikzay A, Stavridi ES, Halazonetis TD (1999) Phosphorylation of Ser-20 mediates stabilization of human $\mathrm{p} 53$ in response to DNA damage. Proc Natl Acad Sci USA 96: $13777-13782$.

33. Unger T, Juven-Gershon T, Moallem E, Berger M, Vogt Sionov R, Lozano G et al. (1999) Critical role for Ser20 of human $p 53$ in the negative regulation of $p 53$ by Mdm2. EMBO J 18: 1805-1814.

34. Buschmann T, Potapova O, Bar-Shira A, Ivanov VN, Fuchs SY, Henderson S et al. (2001) Jun $\mathrm{NH}_{2}$-terminal kinase phosphorylation of p53 on Thr-81 is important for p53 stabilization and transcriptional activities in response to stress. Mol Cell Biol 21: 2743-2754.

35. Ries SJ, Brandts CH, Chung AS, Biederer CH, Hann BC, Lipner EM et al. (2000) Loss of p14ARF in tumor cells facilitates replication of the adenovirus mutant dl1520 (ONYX-015). Nat Med 6: 1128-1133.

36. Iwabuchi K, Bartel PL, Li B, Marraccino R, Fields S (1994) Two cellular proteins that bind to wild-type but not mutant p53. Proc Natl Acad Sci USA 91: 6098-6102.

37. Hupp TR, Meek DW, Midgley CA, Lane DP (1992) Regulation of the specific DNA binding function of p53. Cell 71: 875-886.

38. Hupp TR, Sparks A, Lane DP (1995) Small peptides activate the latent sequence-specific DNA binding function of p53. Cell 83: 237-245.

39. Choi YI, Jeon SH, Jang J, Han S, Kim JK, Chung H et al. (2001) Notch1 confers a resistance to glucocorticoid-induced apoptosis on developing thymocytes by downregulating SRG3 expression. Proc Natl Acad Sci USA 98: 10267-10272.

40. Hearnes JM, Mays DJ, Schavolt KL, Tang L, Jiang X, Pietenpol JA (2005) Chromatin immunoprecipitation-based screen to identify functional genomic binding sites for sequence-specific transactivators. Mol Cell Biol 25: 10148-10158. 